\title{
GERMINAÇÃO DE SEMENTES DE Salvia splendens Sellow EM DIFERENTES TEMPERATURAS E QUALIDADES DE LUZ
}

\author{
NILSON LEMOS DE MENEZES ${ }^{1}$; SIMONE MEDIANEIRA FRANZIN ${ }^{2}$;TERESINHA ROVERSI ${ }^{3}$; \\ ERIC PASQUALLI NUNES ${ }^{4}$
}

\begin{abstract}
RESUMO - A sálvia (Salvia splendens Sellow) é uma planta da família Lamiaceae que se multiplica por sementes. Sobre ela existe grande interesse ornamental, no entanto, pouco se tem estudado sobre esta espécie, em nossas condições. Este trabalho avaliou o efeito de diferentes temperaturas e qualidades de luz sobre a germinação das sementes de sálvia. Os tratamentos aplicados foram às temperaturas de 15,20 e $25^{\circ} \mathrm{C}$ e as luzes branca, vermelha (V), vermelha extrema (VE) e ausência de luz. A intensidade luminosa foi produzida por quatro lâmpadas de $20 \mathrm{~W}$, fixadas internamente na porta do germinador. As qualidades de luz foram obtidas pela cobertura, com papel celofane, das caixas plásticas do tipo gerbox, onde foram semeadas as sementes. A luz V foi obtida pela cobertura das gerbox com duas folhas de celofane vermelhas e para a luz VE utilizaram-se duas folhas vermelhas mais duas folhas azuis. Para a obtenção da luz branca nenhum papel celofane foi colocado sobre as caixas plásticas. A ausência de luz foi obtida pela cobertura das gerbox com papel alumínio. As variáveis testadas foram à germinação, primeira contagem de germinação, índice de velocidade de germinação, comprimento e massa seca das plântulas. A semente de sálvia comporta-se como indiferente à luz, embora germine melhor na luz vermelha extrema e na ausência de luz, também, é capaz de germinar nas luzes branca e vermelha. As temperaturas de 15,20 e $25^{\circ} \mathrm{C}$ afetam a velocidade de germinação das sementes, sendo que $15^{\circ} \mathrm{C}$ retarda o processo germinativo.
\end{abstract}

Termos para indexação: análise de sementes,, fotoblastismo, planta ornamental.

\section{SEEDS GERMINATION OF Salvia splenden Sellow IN TEMPERATURE AND LIGHT QUALITY DIFERENTS}

\begin{abstract}
The salvia (Salvia splendens Sellow) is a plant of the Lamiaceae family, with seed multiplication. There is a great ornamental interest in it but little has been studied about this species, in Brazilian conditions. This study evaluated the effect of different temperatures and light qualities on salvia seed germination. The applied treatments were the temperatures of 15,20 and $25^{\circ} \mathrm{C}$ and the lights white, red (V), far red (VE) and light absence. The luminous intensity was produced by four $20 \mathrm{~W}$ lamps, fastened internally in the door of the germination chamber. The light qualities were obtained by the covering, the plastic gerbox-type boxes with cellophane, where the seeds were sown. The V light was obtained by the covering the gerbox with two red cellophane leaves and two red leaves with two blue leaves blue were used to obtain the VE light. No cellophane on the gerbox was used to obtain the white light. The light absence was obtained by covering the gerbox with aluminum foil. The tested variables were germination, first germination counting, germination speed index, length and plantule dry mass. The salvia seed behaves as indifferent to the light, although it germinates better in the far red light and in the light absence but it is also able to germinate in the white and red lights. The temperatures of 15 , 20 and $25^{\circ} \mathrm{C}$ affect the seed germination speed, and $15^{\circ} \mathrm{C}$ delays the germination process.
\end{abstract}

Index terms: seed analysis, photoblastism, ornamental plant.

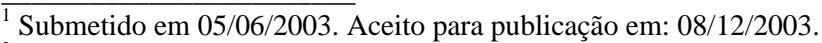

${ }^{2}$ Eng. Agr. Dr., Prof. Adjunto, Depto. Fitotecnia, Campus Universitário, UFSM, 97015-900, Santa Maria - RS, E-mail: nlmenezes@ smail.ufsm.br

${ }^{3}$ Bióloga, Doutoranda do Prog. De Pós-Graduação em Agronomia,
}

Depto. Fitotecnia, UFSM, E-mail: smfranzin@yahoo.com.br ${ }^{4}$ Agr. M.Sc., Doutoranda do Prog. de Pós-Graduação em Agronomia, Depto. Fitotecnia, UFSM, E-mail: tereroversi2001@yahoo.com.br

5 Aluno de Graduação do Curso de Agronomia da UFSM, bolsita da FIPE, Depto. Fitotecnia, UFSM 


\section{INTRODUÇÃO}

A sálvia vermelha (Salvia splendens Sellow) é uma planta anual, também conhecida como alegria dos jardins, que pertence à família Lamiaceae, podendo, porém, comportar-se como espécie bianual, atingindo até $80 \mathrm{~cm}$ de altura, com inflorescências verticiladas ou com espigas e flores tubuladas e ladeadas por brácteas. É originária do Brasil, com utilização intensa em jardins tanto na Europa quanto no Brasil, apresenta uma intensa floração vermelha durante todo o ano, sendo, geralmente, propagada por sementes (Almeida, 2002).

A importação de sementes de países europeus ainda constitui-se na grande fonte para a produção comercial de flores no Brasil. Tal fato estabelece a falta de informações referentes às características genéticas e adaptação às condições ambientais, que dificultam a identificação da qualidade das sementes, permitindo o uso deste insumo com baixa germinação.

Para as condições nacionais, poucos estudos foram realizados até o momento, com sementes de espécies ornamentais, apesar destas, freqüentemente, apresentarem custo elevado e serem produzidas com grau significativo de tecnologia. Além disto, a maioria das espécies apresenta sementes muito pequenas, que dificultam o manuseio e a avaliação de sua qualidade, justificando a necessidade de estudo das sementes de flores e a recomendação, do mercado exigente, para o estabelecimento de programas contínuos de pesquisa em tecnologia de sementes.

A avaliação da qualidade fisiológica, que confere valor para fins de comercialização, é expressa principalmente, pelo teste de germinação, onde cada espécie exige determinadas condições, nas quais as sementes conseguem expressar o máximo potencial, pelo qual podese comparar lotes e determinar o seu valor para a semeadura.

A germinação é uma sequiência ordenada de atividades metabólicas divididas em fases, que resulta na formação de uma plântula (Bewley \& Black, 1994). A percentagem de plântulas normais detectada pelo teste de germinação pode diferir significativamente daquela expressa nas embalagens das sementes, como verificaram Rota \& Nedel (1998) em esporinha (Deiphinuim consolida L.).

A baixa percentagem de germinação ou emergência pode ser uma consequiência de problemas como dormência das sementes, baixo vigor ou devido a fatores ambientais como temperatura, luz, dificuldades de embebição, que por não serem bem conhecidos, dificultam o manuseio $\mathrm{e}$ causam prejuízos.

Dentre os fatores ambientais que afetam o processo germinativo, a temperatura exerce uma influência significativa. Sabe-se que a temperatura afeta a percentagem, velocidade e uniformidade de germinação e está relacionada com os processos bioquímicos. O período de germinação pode mudar completamente em resposta à temperatura, devido à complexidade do processo germinativo (Copeland \& McDonald, 1995). A germinação será mais rápida e o processo mais eficiente, quanto maior for a temperatura, dentro de certos limites. A temperatura ótima, para a maioria das espécies cultivadas, encontra-se entre $20-30{ }^{\circ} \mathrm{C}$. Abaixo da temperatura ótima há redução da velocidade do processo, o que pode também levar a uma redução no total de germinação. Os limites extremos de temperatura e a ótima, constitue-se nas chamadas temperaturas cardiais (Carvalho \& Nakagawa, 2000), não indicadas na literatura para a espécie em estudo.

A luz é necessária para germinação das sementes de várias espécies. A ativação das sementes pela luz está ligada a um sistema de pigmentos denominado fitocromo. Esse pigmento se encontra em todas as plantas superiores, que ao absorver luz num determinado comprimento de onda, muda de estrutura bioquímica e permite, ou não, a resposta fotomorfogenética (Borges \& Reno, 1993). Aparentemente, o fitocromo está sempre associado ao funcionamento das membranas biológicas, regulando, provavelmente, sua permeabilidade e controlando dessa maneira, o fluxo de inúmeras substâncias dentro das células e entre elas (Taiz \& Zeiger, 1991).

A sensibilidade da semente ao efeito da luz varia de acordo com a qualidade, a intensidade luminosa e tempo de irradiação, bem como com o período e temperatura de embebição (Toole, 1973; Labouriau, 1983).

As bases do fotoblastismo foram desenvolvidas com sementes de alface cv. "Grand Rapid" e os estudos mostraram que o comprimento de onda no espectro vermelho estimula a germinação, ao passo que a do espectro do vermelho distante causa inibição da germinação desta espécie (Carvalho \& Nakagawa, 2000). Em relação à luz vermelha, Thomas (1974) destaca que existe efeito semelhante desta com a luz branca no que se refere à composição espectral e características de absorção do fitocromo.

Em espécies florestais, mais do que nas espécies ornamentais, estudos têm se dedicado a avaliar o efeito da qualidade da luz sobre a germinação. Em Mimosa scabrella, Chorisia speciosa, Tabebuia avellanedae e Esenbeckia leiocarpa, a germinação das sementes é maior no escuro, decrescendo na seguinte ordem: luz vermelha, azul, branca e vermelha-distante (Dias et al., 1992). Sementes de Mimosa bimucronata apresentam maior velocidade de germinação na luz branca (Grande \& Takaki, 1998). Já sementes de Peltophorum dubium Taub não apresentaram diferença na percentagem de germinação, quando exposta a luz branca, vermelha, vermelha-extrema e ausência de luz (Perez et al., 1999).

O presente trabalho teve como objetivo avaliar os efeitos de diferentes temperaturas e qualidades de luz sobre a germinação de sementes de sálvia. 


\section{MATERIAL E MÉTODOS}

O trabalho foi realizado no Laboratório Didático e de Pesquisas em Sementes (LDPS), do Departamento de Fitotecnia, na Universidade Federal de Santa Maria, em Santa Maria/RS, no ano de 2001.

Foram utilizadas para o experimento sementes de sálvia (Salvia splendens Sellow), armazenadas sob condições de câmara seca (temperatura de $12{ }^{\circ} \mathrm{C}$ e umidade relativa do ar de 45 a 50\%).

Para avaliar a germinação e o desenvolvimento inicial das plântulas de sálvia, aplicaram-se como tratamentos às combinações dos seguintes fatores: temperaturas de 15,20 e $25^{\circ} \mathrm{C}$ e quantidades de luz, branca, vermelha, vermelho extrema e ausência de luz.

Para se obter a luz branca, as caixas plásticas do tipo gerbox, contendo as sementes, foram expostas à luz produzida por quatro lâmpadas fluorescentes $(20 \mathrm{~W})$, fixadas internamente na porta do germinador, proporcionando uma densidade de fluxo, aproximada de 0,012 w.m. $\mathrm{m}^{-2} \cdot \mathrm{nm}^{-1}$ (Cardoso, 1995). A ausência de luz foi obtida pelo uso de papel laminado envolvendo as caixas gerbox. A luz vermelha foi obtida a partir da luz branca que ultrapassou duas folhas de papel celofane vermelho, envolvendo as caixas gerbox e a luz vermelha extrema obtida a partir da cobertura das caixas gerbox com duas folhas de papel celofane azul e duas folhas de papel celofane vermelho, conforme indicações de Almeida \& Mundstock (2001).

As sementes foram submetidas aos seguintes testes:

1) germinação - utilizaram-se quatro repetições de 100 sementes semeadas em caixas do tipo gerbox, sobre papel, umedecido com água destilada na quantidade correspondente a três vezes o peso do papel substrato. As sementes foram colocadas em germinador nas diferentes temperaturas e qualidades de luz, escolhidas como tratamentos. As avaliações das plântulas foram realizadas aos 7 e 21 dias, conforme Brasil (1992);

2) primeira contagem - foi realizada conjuntamente com o teste de germinação e constou do registro da percentagem de plântulas normais no sétimo dia após a instalação do teste;

3) índice de velocidade de germinação (IVG) utilizaram-se 400 sementes, divididas em quatro repetições iguais, semeados em caixas do tipo gerbox, sobre papel umedecido com água destilada, do mesmo modo como no teste de germinação. Para cada repetição calculou-se o IVG somando-se o número de plântulas normais germinadas a cada dia, dividido pelo respectivo número de dias transcorridos a partir da data de semeadura. Esse procedimento foi adotado até a germinação atingir valor constante (Vieira \& Carvalho, 1994);

4) comprimento e massa seca das plântulas foram utilizadas quatro repetições de 10 plântulas para cada tratamento, retiradas ao acaso do teste de germinação, quando feita a primeira contagem. Determinou-se o comprimento médio das plântulas normais utilizando-se régua milimetrada. Em seguida, foi determinada a massa seca das mesmas plântulas, em estufa a $60{ }^{\circ} \mathrm{C}$, onde elas permaneceram até atingir peso constante. $\mathrm{O}$ comprimento foi determinado em $\mathrm{cm} /$ plântula e a massa seca em mg/plântula.

Análise estatística - Os tratamentos constituíram um experimento fatorial $3 \times$ x 4 (3 temperaturas $\times$ qualidades de luz), com quatro repetições, no delineamento inteiramente casualizado. Foi realizada a análise de regressão polinomial para os valores quantitativos e os dados obtidos em percentagem foram transformados em arcosen. Utilizou-se o Sistema de Análise Estatística para Microcomputadores - SANEST (Zonta et al., 1986).

\section{RESULTADOS E DISCUSSÃO}

Na Figura 1 estão apresentados os resultados da percentagem de germinação das sementes de sálvia, submetidas a diferentes temperaturas e qualidades de luz.

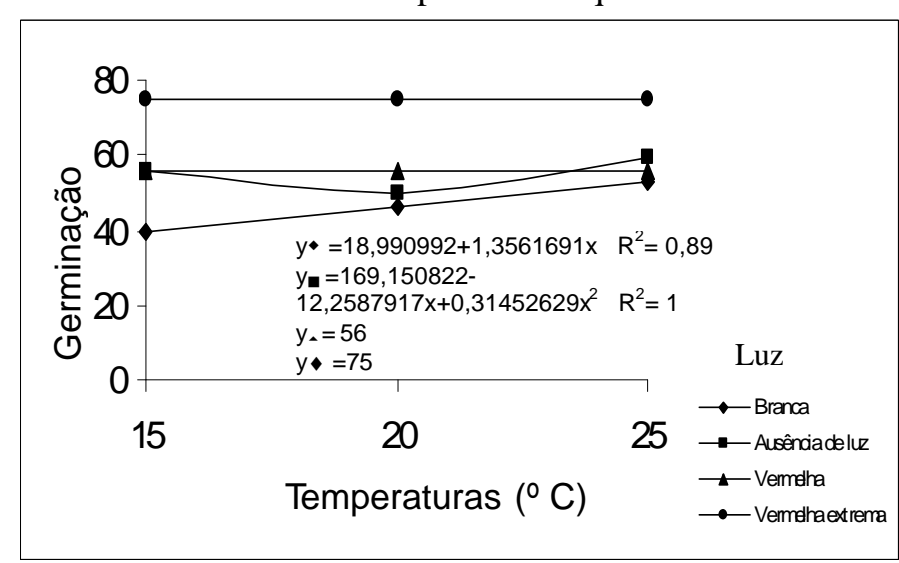

FIGURA 1. Percentagem de germinação de sementes de Salvia splendens submetidas a diferentes temperaturas e qualidades de luz.

A percentagem de germinação variou em função da qualidade de luz, porém na luz branca e na ausência de luz ocorreram variações em consequiência das temperaturas. Os maiores resultados foram observados a 20 e $25{ }^{\circ} \mathrm{C}$ na luz VE $(75 \%)$ e a menor germinação foi alcançada com a luz branca na temperatura de $15{ }^{\circ} \mathrm{C}(39 \%)$. A luz vermelha extrema permitiu a maior germinação nas temperaturas estudadas, ocorrendo também germinação na ausência de luz, sendo assim, a sálvia diferiu das espécies classificadas como fotoblásticas positivas, que não germinam nestas condições (Carvalho \& Nakagawa, 2000).

As sementes de sálvia, de acordo com VasquezYanes \& Orosco-Segovia (1993), podem ser classificadas como insensíveis à luz, por germinarem tanto na ausência como na presença de luz, como ocorre em sementes de 
malva (Figueiredo \& Popinigis, 1980). Porém, para Takaki (2001), que recomenda a forma do fitocromo para classificar a reação das sementes frente à luz, pode-se dizer que a sálvia possui fitocromo na forma ativa suficiente para induzir a germinação na ausência da luz e na forma fiA, que controla a germinação através da resposta de fluência muito baixa.

Os resultados da primeira contagem estão apresentados na Figura 2, onde se verifica maior percentagem de plântulas normais com o aumento da temperatura, sendo a temperatura de $15^{\circ} \mathrm{C}$ prejudicial à velocidade de formação de plântulas, realizada aos sete dias após a semeadura. Esses resultados são explicados, pelo fato de baixas temperaturas reduzirem as taxas metabólicas, até que estas, em temperaturas abaixo das essenciais ao início da germinação não possam mais operar (Hendricks \& Taylorson, 1976; Carvalho \& Nakagawa, 2000).

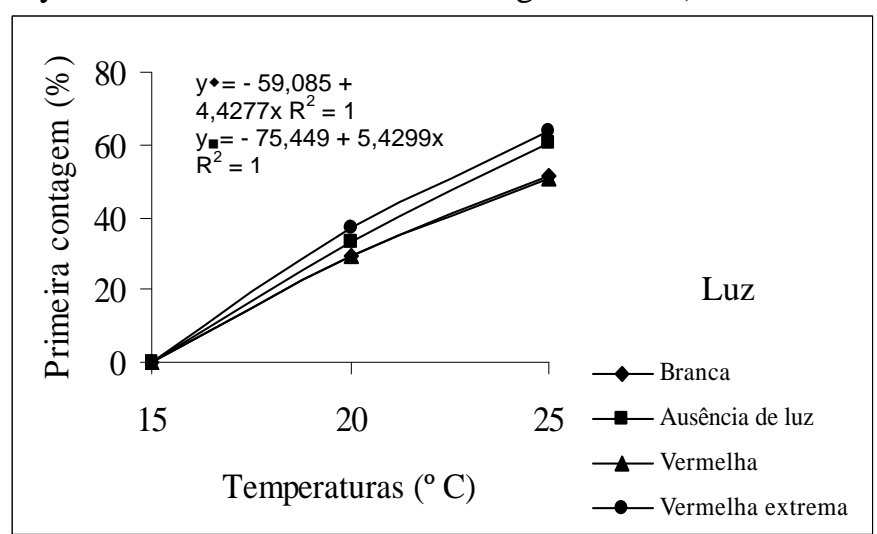

FIGURA 2. Percentagem de plântulas normais no teste de primeira contagem da germinação aplicado em sementes de Salvia splendens, submetidas a diferentes temperaturas e qualidades de luz.

A qualidade da luz não afetou a quantidade de plântulas normais observadas na primeira contagem da germinação. Porém, foram observadas diferenças entre tratamentos, quando a $15{ }^{\circ} \mathrm{C}$ a percentagem foi zero e a 25 ${ }^{\circ} \mathrm{C}$ a percentagem máxima foi de $63 \%$, na luz VE. Esses resultados confirmam a influência da temperatura sobre a germinação das sementes, a qual pode afetar a percentagem final bem como a velocidade e uniformidade do processo (Copeland \& McDonald, 1995; Carvalho \& Nakagawa, 2000; Kraemer et al., 2000).

Em virtude dos tratamentos quantitativos e do não ajuste de equações para as variáveis IVG, comprimento de plântula e massa seca, os resultados foram apresentados na forma de histograma (Figura 3). Observa-se que o IVG aumentou com o acréscimo da temperatura, sem haver, contudo, diferença entre os resultados provenientes das temperaturas de 20 e $25{ }^{\circ} \mathrm{C}$. Esses resultados estão de acordo com aqueles obtidos por vários autores, entre eles Carvalho \& Nakagawa (2000) e Bewley \& Black (1994), os quais indicaram que a germinação será tanto mais rápida e o processo mais eficiente, quanto maior for a temperatura, até certo limite.

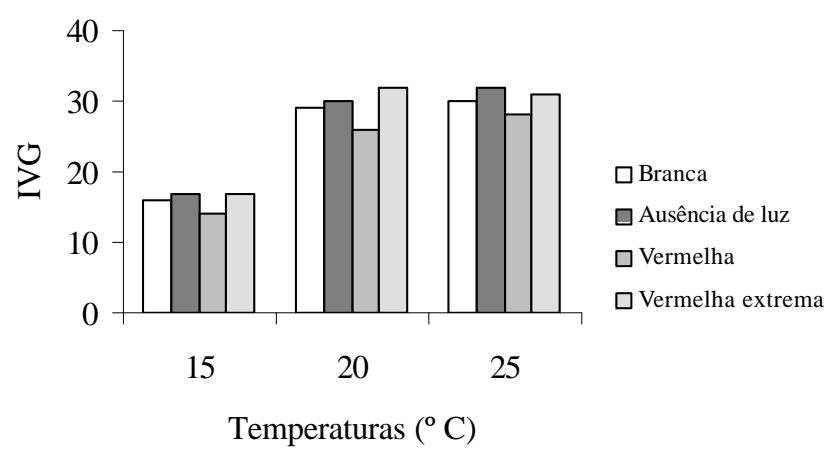

(b)

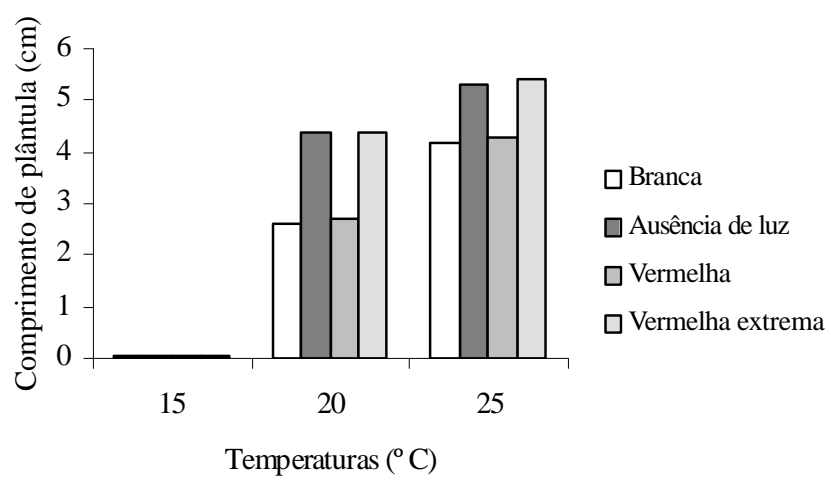

(c)

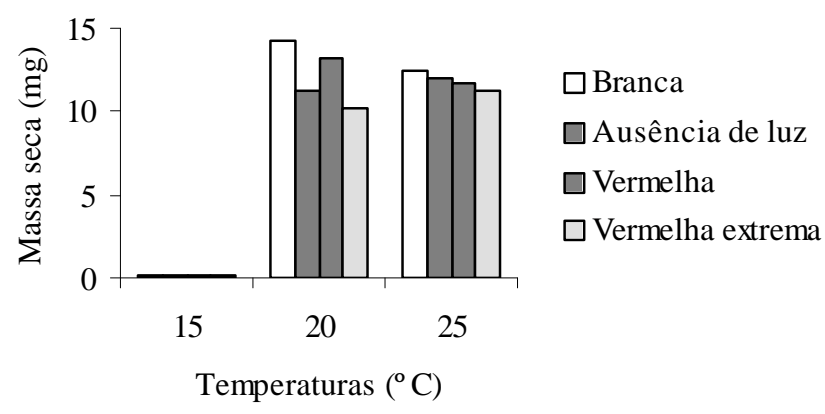

FIGURA 3. (a) Índice de Velocidade de Germinação (IVG), (b) comprimento de plântulas (cm) e (c) massa seca de plântulas de Salvia splendens, após germinação das sementes em diferentes temperaturas e qualidades de luz 
A qualidade de luz não influenciou o IVG nas temperaturas testadas, pois a velocidade de germinação parece ser mais influenciada pela temperatura. Observou-se, porém, que a luz $\mathrm{V}$ determinou valores absolutos de IVG inferiores em todas as temperaturas.

Os resultados relativos ao comprimento de plântulas, observados na Figura 3b, indicaram que os valores absolutos encontrados na temperatura de $25{ }^{\circ} \mathrm{C}$ foram maiores do que na temperatura de $20{ }^{\circ} \mathrm{C}$.

A associação entre temperatura e luz mostrou que nas temperaturas de 20 e $25^{\circ} \mathrm{C}$, a ausência de luz e a luz vermelha extrema tiveram efeitos semelhantes sobre o comprimento das plântulas. Tais efeitos foram superiores àqueles verificados com o uso das outras qualidades de luz. A luz vermelha extrema e a ausência de luz estimulam o alongamento celular (Whatley \& Whatley, 1982), como foram observados nesses resultados. A luz branca e a vermelha, devido à composição espectral e características de absorção do fitocromo tiveram efeitos semelhantes, como havia anunciado Thomas (1974), enquanto a temperatura de $15^{\circ} \mathrm{C}$ retardou a germinação das sementes e impossibilitou a avaliação do comprimento das plântulas.

Com relação à massa seca (Figura 3c), constatou-se pequenas variações nos valores absolutos (10 a $14 \mathrm{mg}$ ) obtidos nas temperaturas de 20 e $25{ }^{\circ} \mathrm{C}$. Na temperatura de $15{ }^{\circ} \mathrm{C}$ não se obteve plântulas normais para realização do teste. A luz branca na temperatura de $20{ }^{\circ} \mathrm{C}$ apresentou valores de massa seca maior $(14,2 \mathrm{mg})$ do que nas demais qualidades de luz, enquanto que a luz vermelha extrema (10,2 mg), foi a que determinou menor massa seca das plântulas.

$\mathrm{Na}$ temperatura de $25{ }^{\circ} \mathrm{C}$, verificou-se maior uniformidade nos resultados produzidos pelas diferentes qualidades de luz, quando ocorreu maior transferência de reservas dos tecidos de armazenamento e maior incorporação destas pelo eixo embrionário. A luz branca, no entanto, quando associada a esta temperatura, novamente, permitiu maior valor de massa seca do que a luz VE.

\section{CONCLUSÕES}

A semente de sálvia (Salvia splendens Sellow) comporta-se como indiferente à luz. Embora germine melhor na luz vermelha extrema e na ausência da luz, também, é capaz de germinar nas luzes branca e vermelha.

As temperaturas de 15,20 e $25^{\circ} \mathrm{C}$ afetam a velocidade de germinação das sementes de sálvia, sendo que $15^{\circ} \mathrm{C}$ retarda o processo germinativo.

\section{REFERÊNCIAS}

ALMEIDA, D. Salvia splendens, Disponível em: <http://www.dalmeida.com/floricultura/fichas/Salvia1.htm>. Acesso em: 10 de jun. 2002.
ALMEIDA, M.L.; MUNDSTOCK, C.M. A qualidade da luz afeta o afilhamento em plantas de trigo quando cultivadas sob competição. Ciência Rural, Santa Maria, v.31, n.3, p.401-408, 2001.

BEWLEY, J.D.; BLACK, M. Seeds: physiology of development and germination. 2ed. New York: Plenum Press, 1994. 445p.

BORGES, E.E.L.; RENA, A.B. Germinação de sementes. In: AGUIAR, I.B.; PINÃ-RODRIGUES, F.C.M.; FIGLIOLIA, M.B. (Coord.). Sementes florestais tropicais. Brasília: ABRATES, 1993. p.83-135.

BRASIL. Ministério da Agricultura e Reforma Agrária. Regras para análise de sementes. Brasília: SNDA/DNDV/CLAV, 1992. 365p.

CARDOSO, V.J.M. Germinação e fotoblastismo de sementes de Cucumis anguria: influência da qualidade da luz durante a maturação e secagem. Revista Brasileira de Fisiologia Vegetal, Brasília, v. 7, n.1, p.75-80, 1995.

CARVALHO, N.M.; NAKAGAWA, J. Sementes: ciência, tecnologia e produção. 4ed. Jaboticabal: FUNEP, 2000, $588 \mathrm{p}$.

COPELAND, L.O.; McDONALD, M. Principles of seeds science and technology. New York: Chapman Hall, 1995. 409p.

DIAS, L.A.S.; KAGEYAMA, P.Y.; ISSIKI, K. Qualidade de luz e germinação de espécies arbóreas tropicais. Acta Amazônica, Manaus, v.22, n.1, p.79-84, 1992.

FIGUEIREDO, F.J.C.; POPINIGIS, F. Temperatura de germinação para sementes de malva. Revista Brasileira de Sementes, Brasília, v. 2, n. 2, p.9-22, 1980.

GRANDE, F.G.A.F.; TAKAKI, M. Efeito da temperatura e luz na germinação de sementes de Mimosa bimucronata (Mimosaceae). In: CONGRESSO NACIONAL DE BOTÂNICA, 49., 1998, Salvador. Resumos... Salvador: UFBA, Instituto de Biologia, 1998. p.186.

HENDRICKS, S.B.; TAYLORSON, R.B. Variation in the germination and amino acid leakage of seeds with temperature relate to membrane phase change. Plant Physiology, Minneapolis, v.58,n.1, p.7-11, 1976.

KRAEMER, K.H.; KÂMPF, A.N.; ÁQUILA, M.E.A. Luz e temperatura na geminação de sementes de Tibouchina urvilleana. Revista Brasileira de Horticultura Ornamental, Campinas, v.6, n.1/2, p.39-45, 2000.

LABOURIAU, L.C. A germinação das sementes. Washington: OEA, 1983. 174p. 
PEREZ， S.C.J.G.A.; FANTI， S.C.; CASALI， C.A. Dormancy break and light quality effects on seed germination of Peltophorum dubium Taub. Revista Árvore, Viçosa, v.23, n.2, p.131-137, 1999.

ROTA, G.; NEDEL, J.L. Qualidade fisiológica de sementes de ssporinha (Delphinium consolida L.). Revista Brasileira de Agrociência, Pelotas, v. 4, n. 3, p.183-186, 1998.

TAKAKI, M. New proposal of classification of seeds based on forms of phytochrome instead of photoblastism. Revista Brasileira de Fisiologia Vegetal, Brasília, v.13, n.1, p.103107, 2001.

THOMAS, H. Control mechanisms in the resting seeds. In: ROBERTS, E.H. (Ed.) Viability of seeds. London: Chapman and Hall, 1974. p.360-396.

TAIZ, L.; ZEIGER, E. Plant physiology. Redwood City: Cummings, 1991. 565p.
TOOLE, V.K. Effects of light, temperature and their interactions on the germination of seeds. Seed Science and Technology, Zürich, v.21, n.1, p.339-396, 1973.

VAZQUEZ-YANES, C.; OROSCO-SEGOVIA, A. Patterns of seed longevity and germination in the tropical rainforest. Annual review of ecology and systematics, Stanford, v.24, p.69-87, 1993.

VIEIRA, R.D.; CARVALHO, N.M. Testes de vigor em sementes. Jaboticabal: FUNEP, 1994. 164p.

WHATLEY, J.M.; WHATLEY, F.R. A luz e a vida das plantas. São Paulo: EPU, 1982. 100p.

ZONTA, E.P.; SILVEIRA, P.S.; ALMEIDA, A. Sistema de análise estatística para microcomputadores SANEST. Pelotas: Instituto de Física e Matemática, UFPel, 1986. 